\title{
Comparative study of endonasal dacryocystorhinostomy with and without adjunctive topical use of mitomycin c
}

\begin{abstract}
Endoscopic dacryocystorhinostomy has now established itself in the treatment of lacrimal obstruction. This surgical technique employed by ENT surgeons, has certain advantages over the more conventional external dacryocystorhinostomy performed by ophthalmologists. Failures in endoscopic dacryocystorhinostomy are mainly due to reclosure of the stoma in the lateral nasal wall. Mitomycin-C is an Alkylating agent used in the chemotherapy of various cancers. Mitomycin- $\mathrm{C}$ when topically applied to mucosal tissues has been reported to inhibit excessive scar tissue and granulation tissue formation, resulting in greater success rates. To evaluate the efficacy of Mitomycin-C in preventing reclosure of the dacryocystorhinostomy stoma we performed a prospective, randomized case control study between November 2013 and October 2015. The study was conducted at tertiary care centre.

The study sample consisted of 50 patients, who were randomly assigned to two groups, a Group A which received the application of Mitomycin - C topically to the dacryocystorhinostomy stomal site and Group B which did not receive this intervention. The patients were regularly followed up for 6months. 24 patients $(96 \%)$ out of 25 in the Group A, had a successful surgical outcome. In Group B 23 patients (92\%) out of 25 were symptom free after surgery. These results indicated no statistically significant difference between the two groups $(\mathrm{p}>0.05)$. Hence the results of this study did not show any significant benefit for the use of Mitomycin- $\mathrm{C}$ as an adjunct during primary endoscopic dacryocystorhinostomy. An atraumatic and meticulous surgical technique along with a good follow up care post-operatively establishes Endoscopic Dacryocystorhinostomy as an effective treatment modality for Chronic Dacryocystitis.
\end{abstract}

Keywords: chronic dacryocystitis, endonasal dacryocystorhinostomy, mitomycin c
Volume 7 Issue 2 - 2017

\author{
Ganesh Kulkarni \\ Govt Medical College, India
}

Correspondence: Ganesh Kulkarni Govt Medical College Moti nagar Latur Maharashtra, India, Tel 8657I 52535, Email kulkarniganesh7sep@gmail.com

Received: April 04, 2017 | Published: May II, 2017

\section{Introduction}

The Lacrimal apparatus starts from the lacrimal gland and ends at the Nasolacrimal ducts. The apparatus consists of the lacrimal gland and the lacrimal pathway. The integrity of the Lacrimal Apparatus in its secretory function and in its drainage mechanism is most vital for the normal functioning of the eye. Any factor which upsets the drainage mechanism distal to the sac or at the Nasolacrimal duct level can lead to the clinical condition of Dacryocystitis.

The incidence of nasolacrimal duct obstruction is estimated to involve approximately 10 percent at 40 years increasing to 35 40 percent at 90 years of age. ${ }^{1,2}$ Epiphora is the primary symptom. However stasis of tears in the lacrimal sac causes recurrent infections of the sac leading to chronic dacryocystitis. The traditional treatment for chronic Nasolacrimal duct obstruction has conventionally been surgery, in the form of an External Dacryocystorhinostomy performed by an ophthalmic surgeon.

The Endonasal approach was introduced in 1893 by Caldwell ${ }^{3}$ and was later modified by West ${ }^{4}$ and Halle. ${ }^{5}$ McDonough and Meiring in 1989 published the first clinical study on the technique of Endoscopic Dacryocystorhinostomy. ${ }^{6}$ In this method, the lacrimal sac is approached through the nasal cavity using nasal endoscopes En DCR. The advantages of this approach are avoidance of a facial scar, maintenance of the normal lacrimal pump mechanism, avoids disruption of the medial palpebral ligament and angular vessels, and prevents trauma to the medial orbital tissues, which can occur in an External Dacryocystorhinostomy operation.
Furthermore any concomitant nasal pathology contributing to Nasolacrimal duct obstruction, such as enlarged agger nasi cells can also be corrected simultaneously. Success rates for En DCR varies from $82 \%$ to $95 \%{ }^{7,8}$ when compared to EXT DCR, which has success rates ranging from $90 \%$ to $97 \% .^{9-11}$ Despite the above mentioned advantages of En DCR, the success rate of the surgery has been less compared to the traditional approach of EXT DCR. The aim of En DCR is to not only establish a free passage between lacrimal sac and nasal cavity but also to keep this passageway patent. In order to enhance the success rate, the causes of failure must be studied in depth. Literature on this subject ${ }^{7}$ points to reclosure of the stoma as the most frequent cause for failure of DCR. Reclosure is due to scarring, adhesions and granulation tissue formation. Topical application of Mitomycin-C, an anticancer drug is said to suppress fibrosis and vascular In growth and possibly enhance success rates. Selig and Co-workers ${ }^{12}$ have claimed that, when Mitomycin-C in concentrations of $0.2 \mathrm{mg}$ per $\mathrm{ml}$ is applied topically to the DCR stomal site, it decreases scarring and adhesions postoperatively. Hence stomal patency is maintained in turn decreasing the failure rate of En DCR Apuhan et al., ${ }^{13}$ and group performed a retrospective study on effect of Mitomycin- C in En DCR involving 43 patients in Turkey. They found that Mitomycin-C used in $0.5 \mathrm{mg} / \mathrm{ml}$ for 2.5 minutes Intraoperatively had a success rate of $91 \%$ compared to EXT DCR, which had a $71.5 \%$ success rate. However a study performed by Ghosh $\mathrm{S}^{14}$ and group and another by Zilelioglu et al., ${ }^{15}$ has shown no changes in long term outcome with the drug. Few studies regarding the efficacy of this drug have been undertaken and further studies are needed to determine and confirm the efficacy 
of this drug in preventing post-operative closure of the stomal site in the lateral nasal wall. Therefore an attempt is made here to determine, whether Mitomycin-C can influence the success rate of En DCR.

\section{Materials and methods}

This is a randomized clinical trial done on fifty patients with postsaccal obstruction to the lacrimal pathway, between November 2013 and October 2015. This study was conducted at our tertiary care hospital. The study sample was randomly grouped into two groups; Group A and a Group B using a random number generator. The follow-up period for patients was done at 1 week, 15 day, 1 month, 3 month and 6 months post-surgery.

Patients who entered the study were selected on the basis of the following inclusion criteria:

A. Patients with symptoms of chronic lacrimal obstruction such as Epiphora and mucoid or purulent discharge from the eye.

B. The site of obstruction being distal to the lacrimal sac in Nasolacrimal duct. The exclusion criteria for patients in this study were as follows:

i. Patients with stenosis of the lacrimal puncta and lacrimal canaliculi were not included in this study.

ii. Revision cases of DCR are excluded.

iii. Patients having Nasolacrimal duct obstruction secondary to Trauma, malignancy and underwent total maxillectomy surgery.

iv. Lower eyelid laxity

\section{Surgical technique}

\section{Preoperative evaluation}

Patients with symptoms of Nasolacrimal duct obstruction are examined by an ophthalmologist. The visual acuity of the patient is determined and syringing of the lacrimal sac is performed with normal saline to check the patency of the Nasolacrimal duct. Failure of saline to flow into the nose or regurgitation of saline through the superior Punctum indicates Nasolacrimal duct obstruction. Canalicular probing was also performed for all patients. After a diagnosis of Nasolacrimal duct obstruction is established, the nose on the side to be operated is thoroughly examined for any evidence of Endonasal cause for the Nasolacrimal duct obstruction, such as sinonasal disease, enlarged agger nasi cells, deviated nasal septum or other anatomical abnormalities and variations that could contribute to the obstruction of tear flow. CT scans are not performed. Routine blood investigations and other relevant investigations like Dacryocystograph were done when required. Acute Dacryocystitis cases were treated on medical line and subjected for surgery later.

\section{Anesthesia}

All cases were operated under General Anaesthesia. Topical Anaesthesia and shrinkage of the nasal mucous membrane is achieved by packing the nasal cavity with strips of cotton pledgets soaked in topical 4\% Lignocaine with 1:30,000 adrenaline for fifteen minutes prior to surgery In patients grouped as cases, a cotton pledget soaked in Mitomycin- $\mathrm{C}$ in a concentration of $0.1 \mathrm{mg}$ per $\mathrm{ml}$ was placed in the stomal site for 5 minutes and later removed.

\section{Post-operative care}

The patient is shifted to the ward and is nursed in a semi recumbent position. A broad spectrum antibiotic such as ciprofloxacin 500mg twice a day orally is given for five days. Systemic decongestants and analgesics are prescribed for three days. The anterior nasal pack is removed after 24hours. Topical nasal decongestants applied for 3 times per day for next one week. Antibiotic steroid eye drops one drop every $2 \mathrm{hrs}$ into lower conjunctiva for next 2 weeks. Crusts and debris in the nasal cavity are removed after 48 hours and the patient is discharged from the hospital.

\section{Observation and results}

A Sample size of 50 patients was decided for the study. Out of 50 patients selected for the study, there were 30 female and 20 male patients, with ages ranging from 11years to 65 years, most belonging to third and fourth decade of life. All patients in the study sample underwent an En DCR Patients grouped as cases, had $0.1 \mathrm{mg} / \mathrm{ml}$ Mitomycin-C applied to the stomal opening in the lateral wall of the nose for a period of 5minutes after which a saline wash was given. Patients grouped as controls did not receive this intervention The patients were followed up at 1 st week, 15 day, 1 month, 3month and 6months after Surgery. The patients were subjectively assessed by relief of symptoms they had prior to surgery. They were also assessed objectively by performing sac syringing and nasal endoscopy of each patient came for follow up (Table 1).

Table I Follow up of patient performed nasal endoscopy

\begin{tabular}{lll}
\hline $\begin{array}{l}\text { Findings on } \\
\text { Nasal Endoscopy }\end{array}$ & Group A (N=25) & Group B (N=25) \\
\hline Stomal Patency & Patent 24 (96\%) & Patent 23 (92\%) \\
& Blocked I (4\%) & Blocked 2 (8\%) \\
Synechiae & $3(12 \%)$ & $5(20 \%)$ \\
Granulations & 0 & $3(12 \%)$ \\
\hline
\end{tabular}

Chi square test was used to compare the follow up results for stomal patency and Synechiae while Fischer test was used to compare the follow up granulation as one of the column sample sizes was 0 which returns an Odds ratio of 0 when Chi square test is used. In the above Table 2, it shows $\mathrm{p}$ value is greater than 0.05 ( $\mathrm{p}>0.05)$, which is Statistically insignificant, suggesting that there was no difference observed in various complications at the follow up's b/w the two group The result after applying Chi-square test showed, $\mathrm{p}>0.05$ suggesting that the difference in the results of Group A and Group B was not statistically significant. Hence these results indicate that there is no significant benefit in using Mitomycin-C as an adjunct to prevent stomal closure in En DCR (Table 3). The intra group comparison for NLD patency and NLD blockage was done using Wilcox an Sign Rank test and it suggested that there was a significant difference observed in all the groups at different intervals as $p<0.05$. The inter group comparison was done using Mann Whitney U test, which suggested that there was no siginificant difference in the improvement that was observed in both the groups over the follow up as $p>0.05$. Missing value analysis was performed for those where patient did not show up during the follow up (Table 4).

The occurrence of synechiae was not significantly different in the two groups when compared using Wilcox and sign rank test, $\mathrm{p}=$ 0.162 .3 patients $(12 \%)$ in Group A had minimal granulations around the stomal area, but stomal patency was maintained. The occurrence of synechiae was not significantly different in the two groups when compared using wilcoxan sign rank test, $\mathrm{p}=0.083$ (Table $5 \& 6$ ).

These results were subjected to statistical analysis using the SPSS Trial version 15.0. The result after applying Chi-square 
test showed $X^{2}=0.3546$. ' $\mathrm{p}$ ' value of 0.5515 which is greater than $0.05(\mathrm{p}>0.05)$ was obtained. Therefore the difference in the results of Group A and Group B was not statistically significant. Hence these results indicate that there is no significant benefit in using Mitomycin- $\mathrm{C}$ as an adjunct to prevent stomal closure in En DCR.

Table 2 Statistical Analysis of Follow-Up

\begin{tabular}{|c|c|c|c|c|c|c|}
\hline $\begin{array}{l}\text { Findings on } \\
\text { Nasal Endoscopy }\end{array}$ & Group A $(\mathbf{N}=\mathbf{2 5})$ & Group B ( $\mathbf{N}=\mathbf{2 5})$ & $\times 2$ & $\mathbf{P}$ & Cl & Odds \\
\hline Stomal Patency & Patent 24 (96\%) Blocked I (4\%) & Patent 23 (92\%) Blocked 2 (8\%) & 0.3546 & $0.5515^{*}$ & $\begin{array}{l}0.177- \\
24.615\end{array}$ & 2.08696 \\
\hline Synechiae & $3(12 \%)$ & $5(20 \%)$ & 0.5952 & $0.4404^{*}$ & $0.1|5-2.58|$ & 0.54545 \\
\hline Granulations & 0 & $3(12 \%)$ & & $0.2347^{*}$ & & \\
\hline
\end{tabular}

Table 3 Follow up of postoperative patient by sac syringing

\begin{tabular}{|c|c|c|c|c|c|}
\hline & & NLD patent & NLD Blocked & $\mathbf{Z}$ & $\mathbf{P}$ \\
\hline \multirow[t]{3}{*}{ Ist week } & Group A & 25 & 0 & -4.3723 & 0.000012 \\
\hline & Group B & 25 & 0 & -4.3723 & 0.000012 \\
\hline & $P$ value & I & I & & \\
\hline \multirow[t]{3}{*}{ I5th day } & Group A & 23 & 2 & -4.0145 & 0.00006 \\
\hline & Group B & 24 & I & -4.0145 & 0.00006 \\
\hline & $P$ value & 0.556 & 0.556 & & \\
\hline \multirow[t]{3}{*}{ I month } & Group A & 23 & 2 & -4.0145 & 0.00006 \\
\hline & Group B & 24 & I & -4.0145 & 0.00006 \\
\hline & $P$ value & 0.556 & 0.556 & & \\
\hline \multirow[t]{3}{*}{3 month } & Group A & 23 & 2 & -4.0145 & 0.00006 \\
\hline & Group B & 24 & I & -4.0145 & 0.00006 \\
\hline & $P$ value & 0.556 & 0.556 & & \\
\hline \multirow[t]{3}{*}{6 month } & Group A & 23 & 2 & -4.0145 & 0.00006 \\
\hline & Group B & 24 & I & -4.0145 & 0.00006 \\
\hline & $P$ value & 0.556 & 0.556 & & \\
\hline
\end{tabular}

Table 4 Complications

\begin{tabular}{lll}
\hline Complication & $\begin{array}{l}\text { Group A } \\
(\mathbf{N}=\mathbf{2 5})\end{array}$ & $\begin{array}{l}\text { Group B } \\
(\mathbf{N}=\mathbf{2 5})\end{array}$ \\
\hline Synechiae & $3(12 \%)$ & $5(20 \%)$ \\
Granulations & $0(0 \%)$ & $3(12 \%)$ \\
\hline
\end{tabular}

Table 5 Results

\begin{tabular}{lll}
\hline Complication & $\begin{array}{l}\text { Group A } \\
(\mathbf{N}=25)\end{array}$ & $\begin{array}{l}\text { Group B } \\
(\mathbf{N}=\mathbf{2 5})\end{array}$ \\
Synechiae & $\mathbf{3}(\mathbf{I} \%)$ & $\mathbf{5 ( 2 0 \% )}$ \\
Granulations & $\mathbf{0}(\mathbf{0} \%)$ & $\mathbf{3}(\mathbf{I} \%)$ \\
& Surgery Success & Surgery Failure \\
\hline Group A $(\mathrm{n}=25)$ & $24(96 \%)$ & $\mathrm{I}(4 \%)$ \\
Group B $(\mathrm{n}=25)$ & $23(92 \%)$ & $2(8 \%)$ \\
\hline
\end{tabular}

\section{Discussion}

The study conducted in tertiary care centre of fifty patients presenting with symptoms and signs suggestive of Nasolacrimal duct obstruction .they were assigned randomly into two groups Group A patients with Endonasal DCR with Mitomycin C application and Group B with conventional Endonasal DCR Failures in En DCR are due to reclosure of the stoma (Table 7).

After analyzing the success rates of the above studies, it is clear that the results of En DCR without Mitomycin-C range from $75 \%$ to $96 \%$. Most of the above mentioned studies had a similar follow-up period of approximately 12 months. The application of Mitomycin-c in the form of eye drops as adjunctive treatment for primary and recurrent Pterygia after surgical excision is known to be safe and effective ${ }^{22}$ this led to the use of Mitomycin-C in endoscopic DCR to prevent reclosure of the stoma. Only a few clinical studies, evaluating the efficacy of Mitomycin-C in En DCR have been performed. Various concentrations and different durations of application have been tried, for example $0.5 \mathrm{mg} / \mathrm{ml}$ for $10 \mathrm{~min} 3,0.5 \mathrm{mg} / \mathrm{ml}$ for 5 minutes ${ }^{15}$ and $0.2 \mathrm{mg} / \mathrm{ml}$ for 3 minutes. ${ }^{20}$ They are discussed below (Table 8 ).

Camara et al., ${ }^{23}$ studies showed the success rate of the Mitomycin-C group was statistically significant $(\mathrm{p}=0.007)$ and concluded by stating that the intraoperative use of Mitomycin-C in En DCR is safe and also effective. Zilelioglu et al. ${ }^{15}$ concluded that there is no benefit in using Mitomycin-C in En DCR. Thomas Prasannaraj et al., ${ }^{24}$ concluded that Mitomycin-C did not appear to influence the occurrence of granulations, synechiae, or obliterative sclerosis, nor did it alter the success rate significantly.

In present study we achieved a success rate of $96 \%$ with the drug and $92 \%$ without adjuvant use of drug. The controversy still exists as to whether Mitomycin-C is beneficial or not in preventing reclosure of the stoma. Present study revealed no benefit in using Mitomycin- C as an adjunct in primary En DCR. Our experience is that, creating a large stoma, exposing lacrimal sac fully after removing the maxillary bone surrounding it, adequate marsupialisation of the lacrimal sac and meticulous surgical technique, without causing unnecessary trauma and adjacent raw areas, between the lateral nasal wall and middle turbinate/ Septum is sufficient to ensure a good surgical result in the majority of patients. Preservation of nasal and lacrimal mucosal flaps are helpful.

Inadequate exposure of the entire lacrimal sac, sacrificing of nasal and lacrimal sac mucosa during the procedure and a small opening at the medial wall of the lacrimal sac, have all been said to hamper the success of the endoscopic procedure ${ }^{7,25}$ The incidence of postoperative complications such as synechiae was more when Mitomycin 
C was not used than when it was used, however this difference in results was not found to be statistically significant.

Intraoperative application of drug does not cause any systemic problems since it is not absorbable from gastrointestinal tract . We have not encountered any nasal, ophthalmic or gastric adverse effects after using Mitomycin-C in present study. There have been reports of complications such as corneal ulcers, corneal perforations, scleral calcification in eye surgeries. However generally its use has been found to be safe in En DCR., ${ }^{3,19}$ In present study an attempt was made to remove all the maxillary bone surrounding the lacrimal sac, marsupialise the sac and to ensure a large stoma.

Table 6 Statistical Analysis of Results

\begin{tabular}{lllclll}
\hline Category & Results & & Total & X2, P Value & Cl & Odds Ratio \\
\hline & Surgery Success & Surgery Failure & X2=0.3546 & $\mathbf{0 . 1 7 7 - 2 4 . 6 1 5}$ & $\mathbf{2 . 0 8 6 9 6}$ \\
\hline Cases & 24 & $\mathrm{I}$ & 25 & $\mathrm{P}=0.5515$ & & \\
Control & 23 & 2 & 25 & & & \\
\hline
\end{tabular}

Table 7

\begin{tabular}{lllll}
\hline Author & Year & No. of Patients & Mean follow Up & Results \\
\hline Metson R [17] & 1992 & 46 & 13.2 months & $85 \%$ \\
Sprekelsen MB [16] & 1995 & 152 & 12 months & $96 \%$ \\
Hartikainen J et al. [10] & 1998 & 32 & 12 months & $75 \%$ \\
Cokkeser Y [18] & 2000 & 51 & 25 months & $88.20 \%$ \\
Wormald P] [7] & 2001 & 47 & 11 months & $95.70 \%$ \\
\hline
\end{tabular}

Table 8 Controlled studies of endoscopic dacryocystorhinostomy with and without Mitomycin-C

\begin{tabular}{|c|c|c|c|c|}
\hline Author & Year & & Mean follow Up & Results \\
\hline \multirow[t]{2}{*}{ Zilelioglu et al. [15] } & 1998 & No. of cases 22 & I3.2 months & $85 \%$ \\
\hline & & No. of controls 18 & & \\
\hline \multirow[t]{2}{*}{ Camara [23] } & 2000 & No. of cases 123 & $5 \mathrm{I}$ months & $99.20 \%$ \\
\hline & & No. of controls 48 & 51 months & $89.60 \%$ \\
\hline \multirow[t]{2}{*}{ Thomas Prasannaraj et al. [24] } & 2010 & No. of cases 18 & 6 months & $82.30 \%$ \\
\hline & & No. of control 20 & 6 months & $85.70 \%$ \\
\hline \multirow[t]{2}{*}{ Present study } & $2013-15$ & No. of cases 25 & 6 months & $96 \%$ \\
\hline & & No. of controls 25 & 6 months & $92 \%$ \\
\hline
\end{tabular}

So what should be the ideal follow-up period for these patients and after what period of time after surgery, can the surgeon be confident that there will be no stomal. The answers to these thoughts were given by a few studies. Analysis of Boush et al., ${ }^{26}$ series showed that majority of surgical failures occurred within four months after endoscopic surgery. A similar finding was also seen in Kong et al., ${ }^{27}$ study. They reported that the average onset of stomal closure after the primary operation was 12.7 weeks. Woog et al., ${ }^{28}$ also reported that average onset of failure was 7.8 weeks postoperatively. All of these findings indicate that the critical period is 7 weeks to 13 weeks after endoscopic surgery. In present study, the minimum follow-up period was 6 months. The importance of post-operative care for a period of at least 6 months cannot be understated and has been shown to have a significant effect on the results of surgery. ${ }^{3,19}$

\section{Conclusion}

In present study, the results of endoscopic dacryocystorhinostomy with Mitomycin- C were 96\%, whereas in endoscopic dacryocystorhinostomy without Mitomycin-C, it was $92 \%$ after a minimum follow-up period of 6 months. However, this difference in the results is statistically insignificant $(p>0.05)$. Hence we conclude that Mitomycin-C has no significant beneficial effect in preventing reclosure of the dacryocystorhinostomy stoma after primary endoscopic dacryocystorhinostomy. An adequate bony window, marsupialisation of the lacrimal sac along with preservation of nasal and lacrimal sac mucosa, help in ensuring a good surgical outcome. Meticulous, atraumatic surgical technique is paramount in achieving a successful surgical result. Mitomycin-C can be reserved for patients who come with failure of primary endoscopic DCR surgery or in those cases where follow up is difficult. The incidence of post-operative complications was found to be less when Mitomycin C was used, however, this was not found to be statistically significant.

\section{Acknowledgments}

None.

\section{Conflicts of interest}

Author declares there are no conflicts of interest.

\section{Funding}

None.

\section{References}

1. Neil Fergie, Nicholas S Jones.Dacryocystorhinostomy. In: Michael Gleeson, et al. (Eds,). Scott-Brown's Otorhinolaryngology, Head and Neck Surgery. ( $7^{\text {th }}$ edn), Hodder Arnold, Great Britain, UK. 2008. p.1689-1698.

2. Dalgleish R. Idiopathic Acquired Lacrimal Drainage Obstruction. Br J Ophthalmol. 1967;51(7):463-468.

3. Ragab SM, Elsherif HS, Shehata EM, et al. Mitomycin Cenhanced Revision Endoscopic Dacryocystorhinostomy: A Prospective Randomized Controlled Trial. Otolaryngol Head Neck Surg . 2012;147(5):937-942. 
4. West JM. A Window Resection of The Nasal Duct in Cases of Stenosis Trans Am Ophthalmol Soc. 1910;12(pt 2):654-658.

5. Halle M. Zur Intranasalen Operation Am Tranensack Laryngol Rhinol. 1914;100:41-44.

6. McDonogh M, Meiring JH. Endoscopic Transnasal Dacryocystorhinostomy. J Laryngol Otol. 1989;103(6):585-587.

7. Wormald PJ. Powered Endoscopic Dacryocystorhinostomy. Laryngoscope. 2002;112(1):69-72.

8. Eloy P, Bertrand B, Martinez M, et al. Endonasal Dacryocystorhinostomy: Indications, Technique And Results. Rhinology. 1995;33(4):229-233.

9. Hurwitz JJ, Rutherford S. Computerized Survey of Lacrimal Surgery Patients. Ophthalmology. 1986;93(1):14-19.

10. Hartikainen J, Antila J, Varpula M, et al. Prospective Randomized Comparison Of Endonasal Endoscopic Dacryocystorhinostomy And External Dacryocystorhinostomy. Laryngoscope. 1998;108(12):1861-1866.

11. MukhtarSA,JamilAZ,AliZ. Efficacy of External Dacryocystorhinostomy (Dcr) With And Without Mitomycin-C In Chronic Dacryocystitis. J Coll Physicians Surg Pak. 2014;24(10):732-735.

12. Selig Yk, Biesman Bs, Rebeiz Ee. Topical Application of Mitomycin C in Endoscopic Dacryocystorhinostomy. Am J Rhinol. 2000;14(3):205-207.

13. Apuhan T, Yildirim YS, Eroglu F, et al. Effect Of Mitomycin C On Endoscopic Dacryocystorhinostomy. J Craniofac Surg. 2011;22(6):2057-2059.

14. Ghosh S, Roychoudhury A, Roychaudhuri BK. Use Of Mitomycin-C In Endodcr. Indian J Otolaryngol Head Neck Surg. 2006;58(4):368-369.

15. Zilelioğlu $\mathrm{G}$, Uğurbaş $\mathrm{SH}$, Anadolu $\mathrm{Y}$, et al. Adjunctive Use Of Mitomycin C On Endoscopic Lacrimal Surgery. Br J Ophthalmol . 1998;82(1):63-66.

16. Sprekelsen MB, Barberán MT. Endoscopic Dacryocystorhinostomy: Surgical Technique and Results. Laryngoscope. 1996;106(2 Pt 1):187-189.
17. Metson R Woog JJ, Puliafito CA Endoscopic Laser Dacryocystorhinostomy. Laryngoscope. 1994;104(3 Pt 1):269-274.

18. Cokkeser Y, Evereklioglu C, Er H. Comparative External Versus Endoscopic Dacryocystorhinostomy: Results In 115 Patients (130 Eyes). Otolaryngol Head Neck Surg. 2000;123(4):488-491.

19. Cheng SM, Feng YF, Xu L, et al. Efficacy Of Mitomycin C In Endoscopic Dacryocystorhinostomy: A Systematic Review And MetaAnalysis. Plos One. 2013;8(5):E62737.

20. HarugopAs, Rekha Bk, Mudhol Rs, et al. Randomized Placebo Controlled Trial Of Mitomycin-C In Surgical Outcome Of Primary Endoscopic Dacryocystorhinostomy. Al Ameen J Med Sci . 2013;6(3):231-236.

21. Metson R. Endoscopic Dacryocystorhinostomy. In: Wackym Pa, et al. (Eds.), Minimally Invasive Surgery of the Head, Neck and Cranial Base, Lippincott Williams and Wilkins, Philadelphia, USA. 2002. p.311-318.

22. Singh G, Wilson MR, Foster CS. Mitomycin Drops A Treatment for Pterygium. Ophthalmology. 1988;95(6):813-821.

23. Camara Jg,BengzonAu,Henson Rd. The Safety andEfficacy of Mitomycin $\mathrm{C}$ in Endonasal Endoscopic Laser Assisted Dacryocystorhinostomy. Ophthal Plast Reconstr Surg. 2000;16(2):114-118.

24. Prasannaraj T, Kumar BY, Narasimhan I, et al. Significance Of Adjunctive Mitomycin C In Endoscopic Dacryocystorhinostomy. Am J Otolaryngol . 2012;33(1):47-50.

25. Gupta N. Improving Results In Endoscopic Dcr. Indian J Otolaryngol Head Neck Surg. 2011;63(1):40-44.

26. Boush Ga. Results of Endonasal Laser - Assisted Dacryocystorhinostomy. Ophthalmology. 1994;101:955-959.

27. Kong YT, Kim TI, Kong BW. A Report of 131 Cases Of Endoscopic Laser Lacrimal Surgery. Ophthalmology. 1994;101(11):1793-1800.

28. Woog JJ1, Metson R, Puliafito CA. Holmium: Yag Endonasal Laser Dacryocystorhinostomy. Am J Ophthalmol. 1993;116(1):1-10. 